\title{
Molecular and phenotypic identification of Candida isolates from pregnant women in Ogbomoso, Southwestern Nigeria
}

\author{
Akinbami Abidemi Nurat ${ }^{1}$, Babalola Gbolahan Ola ${ }^{1}$, Shittu Mujeeb Olushola ${ }^{2}$, \\ Tijani Aramide Mikhail ${ }^{3}$, Adekola Saheed Ayodeji ${ }^{2}$
}

\begin{abstract}
${ }^{1}$ Department of Microbiology, Faculty of Science, Obafemi Awolowo University, Ile-Ife, Osun State, Nigeria, ${ }^{2}$ Department of Medical Laboratory Services, Ladoke Akintola University of Technology Teaching Hospital, Ogbomoso, Oyo State, Nigeria,

${ }^{3}$ Department of Obstetrics and Gynaecology, Ladoke Akintola University of Technology Teaching Hospital, Ogbomoso, Oyo State, Nigeria
\end{abstract}

Received: 2 November 2015

Accepted: 12 December 2015

\section{*Correspondence:}

Dr. Akinbami Abidemi Nurat,

E-mail: bideminurat@gmail.com

Copyright: (C) the author(s), publisher and licensee Medip Academy. This is an open-access article distributed under the terms of the Creative Commons Attribution Non-Commercial License, which permits unrestricted non-commercial use, distribution, and reproduction in any medium, provided the original work is properly cited.

\begin{abstract}
Background: Vulvovaginal candidiasis (VVC), often referred to as a yeast infection is a common gynaecologic disease, affecting 3 out of 4 women in their lifetimes. More than $40 \%$ of affected women will have 2 or more VVC episodes, and infection occurs more frequently in pregnant women. This study was carried out to provide information on the appropriate diagnostic method required to differentiate the causative agents of VVC among pregnant women.

Methods: In this study, vaginal specimens were collected from one hundred (100) pregnant women aged between 1744 years and of gestation age of 14-36 weeks who were attending antenatal clinic at LAUTECH Teaching Hospital, Ogbomoso. The species identification was performed using chromogenic medium, induction of fungal germ tube formation, and PCR using universal primers of internal transcriber spacer (ITS1 and ITS4); (ITS1 [5'TCCGTAGGTGAACCTGCGG-3'] and ITS4 [5'-TCCTCCGCTTATTGATATGC-3']) and Candida albicansspecific primers [5'-GGTTTGCTTGAAAGACGGTAG-3'] and [5'-AGTTTGAAGATATACGTGGTAG-3'] that target sequences site of the intergenic spacer region (ITS) of the fungal rRNA genes (18S and 28S) were used for this assay.

Results: Forty (40) Candida species from 100 specimens were isolated in Saboraud dextrose agar (SDA) medium. Of 19 strains of $C$. albicans that were identified by chromogenic agar (CHROMagar), 17 were confirmed as true positive by PCR while 2 were false positive. The CHROMagar had $89.4 \%$ sensitivity and $90.4 \%$ specificity. In comparison, GTT was better in correctly identifying those strains that were confirmed as C. albicans by PCR (Sensitivity=94\%) while CHROMagar was better in identifying the strains that were not confirmed as $C$. albicans by PCR (Specificity $=90.4 \%$ ).

Conclusions: The combine uses of chromogenic agar and PCR have the advantage of efficient differentiation and identification of Candida species.
\end{abstract}

Keywords: Candida isolates, Pregnant women, Molecular identification

\section{INTRODUCTION}

Candida is a part of human flora. It becomes pathogenic when certain conditions are present and becomes opportunistic infection. ${ }^{1}$ The major etiological agent is
Candida albicans, whereas different Candida species can cause a variety of infections, including $C$. tropicalis, $C$. parapsilosis, C. krusei, C. guillermondii, C. glabrata, and C. kefyer which represent many clinical forms of candidiasis. $^{2}$ 
Candidiasis is a primary or secondary mycotic infection caused by members of the genus Candida. ${ }^{3}$ The clinical manifestations may be acute, subacute or chronic. The infection may be localized in mouth, throat, skin, scalp, vagina, nails, bronchi, lungs or in the gastrointestinal tract or become systemic as in septicemia, endocarditis and meningitis. ${ }^{4}$ Candida infections have become a problem of growing significance. ${ }^{5}$ Candidiasis is the most common opportunistic fungal infection. ${ }^{6}$

Vulvovaginal candidiasis (VVC), often referred to as a yeast infection, is a common gynaecologic disease, affecting 3 out of 4 women in their lifetimes. ${ }^{7}$ More than $40 \%$ of affected women will have two or more VVC episodes, and infection occurs more frequently in pregnant women. ${ }^{7,8}$ It is believed that higher estrogen levels and higher glycogen content in vaginal secretions during pregnancy increase a woman's risk of developing VVC. 9 Also women in childbearing years, have episodes of VVC. Vulvovaginal candidiasis is caused by abundant growth of yeast, belonging to the Candida species in the vaginal mucosa. ${ }^{10}$

Generally, women are said to present with clinical symptoms of vulvovaginal candidiasis when the high vaginal yeast count is greater or equal to $105 \mathrm{CFU} / \mathrm{ml}$ of vaginal fluid. ${ }^{11}$ There are however, several reports implicating symptomatic vulvovaginal candidiasis and increase in rate of transmission and spread of HIV infection in several parts of sub-saharan Africa and beyond. ${ }^{12}$ Recurrent vaginal candidiasis is also common in female patients with acquired immune deficiency syndrome (AIDS), suggesting a role for depressed cellmediated immunity in candidiasis. ${ }^{12}$

Appropriate and rapid laboratory assays are important to identify Candida species in clinical samples to diagnose Candidal vulvovaginitis of women. This type of candidiasis can be very important and significant among HIV positive, pregnant, and immunodeficiency women due to the development of systemic candidiasis in this group of patients. ${ }^{13}$

The currently used laboratory assays such as direct microscopy, culture and biochemical methods to detect and identify Candida species accurately, are timeconsuming, and lack the necessary validity. Also, these assays fail to precisely differentiate between the pathogenic Candida species with none or less pathogenic species of Candida. Since vaginal candidiasis is particularly a health concern in pregnant women, a prompt and reliable diagnostic process is vital in order to choose appropriate therapeutic protocol. This study was therefore conducted to provide information on the appropriate diagnostic method required to differentiate the causative agents of candidiasis in pregnant women.

\section{METHODS}

\section{Study area}

This study was carried out at the Department of Microbiology of Obafemi Awolowo University. The participants were recruited at the Ladoke Akintola University of Technology (LAUTECH) Teaching Hospital, Ogbomoso, Oyo State. The hospital is located in Ogbomosho North Local Government Area, Ogbomoso.

\section{Study design}

The study was a cross sectional survey of one hundred (100) pregnant women aged between 17-44 years and of gestation age of 14-36 weeks who were attending routine antenatal clinic for the first time between July 2014 - Jan 2015 at LAUTECH Teaching Hospital in Ogbomoso. Socio-demographic information and obstetric history was obtained from participants by the use of structured questionnaire. Pre-test counseling for sexually transmitted infections (STIs) was given to each subject by a trained counselor before specimens were collected from them.

\section{Inclusion criteria}

Pregnant women on booking at the hospital were included while members of staff of the hospital, patients with previous history of preterm labor or spontaneous abortion and those that did not give their consent were excluded from the study.

\section{Sample collection}

The vaginal smears were obtained from the posterior fornix of the vagina using sterile swabs. The swab sticks were well labeled accordingly. Samples collected were analyzed within one hour of collection. In case of delay, a drop of phosphate buffer saline was added to the swabs stick container and stored in the refrigerator at 4 to $-8{ }^{\circ} \mathrm{C}$ and assayed within 1-3 hours. Positive patients were given post-test counseling and those infected were treated and it was well documented in their case note.

\section{Germ tube test (GTT) to identify C. albicans}

Yeast isolates from Saboraud dextrose agar were screened for germ tube production in serum broth using $0.5 \mathrm{ml}$ of human serum. The broth was dispensed into small test tubes, and each tube was inoculated with yeast colonies from the culture plate. The tube was incubated at $35-37^{\circ} \mathrm{C}$ for 3 hours. A drop of the serum containing the yeast culture was placed on a clean microscope glass slide, and covered with a cover glass. The preparation was examined using the X10 and X 40 objective lenses. Sprouting yeast cells (tube-like outgrowths) also known as germ tubes were observed in positive samples. Germ tube negative species were regarded simply as Candida 
species. When sprouting yeast cells were seen they were reported as C. albicans. Candida glabrata ATCC 22018 was used as negative control. ${ }^{14}$

\section{Cultivation on the selective medium (CHROMagar)}

Isolates from Saboraud dextrose agar (SDA) were inoculated on CHROMagar (Oxoid, Basingstoke, UK) using an inoculating loop and incubated at $37^{\circ} \mathrm{C}$ for 48 hours. The method is based on the differential release of chromogenic breakdown products from various substrates by Candida species following differential exoenzyme activity. ${ }^{15}$ Identification of yeast was done based on the colour of each colony. Using this method, the following Candida species were identified; C. glabrata (wet dark pink colonies), $C$. tropicalis and $C$. dublinensis (wet blue colonies) and $C$. albicans (wet, green colonies). ${ }^{16}$

\section{DNA extraction and amplification}

The DNA of all the 40 isolates was extracted using zymo DNA extraction kit for bacteria and fungi (Inqaba Biotec, South Africa). DNA extraction was done by picking three colonies from the culture plate using sterile loop and suspended into $500 \mu \mathrm{l}$ of distilled water in a microcentrifuge tube. The suspension was centrifuged at $10,000 \mathrm{rpm}$ for $1 \mathrm{~min}$ and the supernatant was discarded. To the sediment, $200 \mu \mathrm{l}$ of distilled water was added after which the cells were dislodged and $750 \mu$ l of lysis solution was added to the tube. This was thoroughly mixed for about $15 \mathrm{~min}$ and vortexed for another $10 \mathrm{~min}$. The lysis tube was spun for $10,000 \mathrm{rpm}$ for $1 \mathrm{~min}$ after which $400 \mu \mathrm{l}$ of the supernatant was transferred into the provided zymo-spin filter and spun at 7,000 rpm for 1 min. Elution buffer was added and centrifuged at 10,000 rpm for 30 seconds to elute DNA. The eluted DNA was stored at $2^{\circ} \mathrm{C}$ until use. The DNA was quantified using nano drop spectrophotometer (Inquaba Biotec, South Africa) and quantified and gel electrophoresis was done to confirm the presence of DNA.

The universal primers of internal transcriber spacer (ITS1 and ITS4); (ITS1 [5'-TCCGTAGGTGAACCTGCGG-3'] and ITS4 [5'-TCCTCCGCTTATTGATATGC-3']), and C.albicans-specific primers [5'GGTTTGCTTGAAAGACGGTAG-3'] and [5'AGTTTGAAGATATACGTGGTAG-3'] that target sequences site of the intergenic spacer region (ITS) of the fungal rRNA genes (18S and 28S) were used for this assay. The PCR mixture consisted of $5 \mu$ l of master mix, $1 \mu \mathrm{l}$ of each primer and $1 \mu \mathrm{l}$ of template DNA make up to $25 \mu \mathrm{l}$ with nuclease free water. All were mixed and vortexed for 1 second and slightly spun at $500 \mathrm{rpm}$ for 1 min. ${ }^{17}$ It was loaded in a thermo cycler alongside with controls and set at an initial denaturation temperature of $95^{\circ} \mathrm{C}$, denaturation at $95^{\circ} \mathrm{C}$, Annealing temperature of $55^{\circ} \mathrm{C}$, and final extension of $72^{\circ} \mathrm{C}$ for 35 cycles. The PCR products were electrophoresed on a $1.5 \%(\mathrm{w} / \mathrm{v})$ agarose gel. Electrophoresis was performed at $100 \mathrm{~V}$ in $1 \mathrm{X}$ TAE buffer gels were stained after electrophoresis in ethidium bromide for 15 minutes and de-stained in distilled water for 30 minutes. Gels were visualized under ultraviolet (UV) light using UVitec trans illuminator (Avebury, Cambridge). C. albicans ATCC 90028, Candida tropicalis ATCC 1909, Candida dublinensis ATCC 10232 and Candida glabrata ATCC 22018 were used as positive control organisms while Escherichia coli ATCC 25922 was used a negative control organism. ${ }^{17}$

\section{Data analysis}

Frequencies were obtained and percentages were calculated for study variables. Statistical Package for Social Sciences (SPSS) version 18.0 (SPSS, Inc., Chicago, Ill) was used for the analysis. Sensitivity and specificity values were determined using graph pad prism 6 (GraphPad Software, Inc. USA).

\section{RESULTS}

Of the 100 pregnant women investigated for candidiasis, four (4) Candida species were identified by PCR. These were $C$. albicans 18(18\%), C. dublinensis 8(8\%), $C$. glabrata $13(13 \%)$ and $C$. tropicalis 1(1\%). Candida albicans yielded an amplicon size of 535 bp, Candida glabrata yielded 871 bp, Candida tropicalis 524 bp and Candida dublinensis 530 bp (Figure 1).

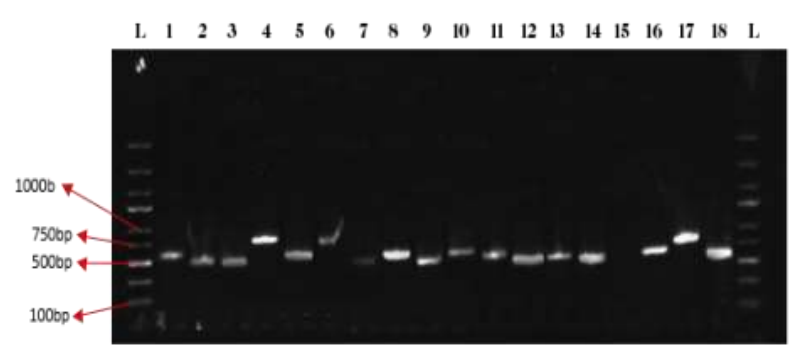

Lane L:1kb ladder, Lane 1: C. albicans control, Lane 2: $C$. dublinensis control, Lane 3: C. tropicalis control, Lane 4: C. labrata control, lane 5: C. albicans, lane 6: C. glabrata, lane 7: C. dublinensis, Lane 8: C. albicans, Lane 9: $C$. tropicalis, Lane 10 and 11: C. albicans, Lane 12: C. dublinensis, Lane 13: C. albicans, Lane 14: C. dublinensis, Lane 15: Negative control, Lane 16: C. glabrata

Figure 1: Agarose gel electrophoresis of Candida species.

The result of phenotypic identification of Candida spp. was compared with genotypic identification as shown in Table 1. Of all the Candida spp. isolated $(\mathrm{n}=40)$, germ tube test identified $21(52.5 \%)$ as C. albicans while 19 $(47.5 \%)$ could not be identified. CHROMagar identified $19(47.5 \%)$ as C. albicans, $11(27.5 \%)$ as C. glabrata, 2 $(5.0 \%)$ as $C$. tropicalis and $8(20 \%)$ were identified as C. dublinensis. All the two isolates that were identified as C. tropicalis by CHROMagar were also confirmed by PCR. Of all the 19 strains of $C$. albicans identified by 
CHROMagar, 2 (10.5\%) were re-identified by PCR as C. glabrata and C. dublinensis (Table 1).

Sensitivity and specificity values of CHROMagar and germ tube test in comparison with the Multiplex PCR for identification of $C$. albicans, $C$. glabrata and C. dublinensis are reported in Table 2. Eighteen (18) strains of $C$. albicans were confirmed as true positive by PCR out of 21 that were identified by GTT as C. albicans. The GTT had $94 \%$ sensitivity and $81 \%$ specificity. Of 19 strains of $C$. albicans that were identified by CHROMagar, 17 were confirmed as true positive by PCR. The CHROMagar had $89.4 \%$ sensitivity and $90.4 \%$ specificity. In comparison, GTT was better in correctly identifying those strains that were confirmed as C. albicans by PCR (Sensitivity=94\%) while CHROMagar was better in identifying the strains that were not confirmed as $C$. albicans by PCR (Specificity $=90.4 \%)$.

Table 1: Comparison of phenotypic identification with genotypic identification of Candida spp.

\begin{tabular}{|c|c|c|c|}
\hline \multirow[b]{2}{*}{ Species } & \multicolumn{2}{|c|}{ Phenotypic method } & \multirow[b]{2}{*}{$\begin{array}{l}\text { PCR } \\
\text { Method }\end{array}$} \\
\hline & $\begin{array}{l}\text { Germ } \\
\text { tube }\end{array}$ & CHROMagar & \\
\hline C. albicans & 21 & 19 & 17 \\
\hline \multicolumn{4}{|c|}{ Other Candida spp } \\
\hline C. glabrata & 0 & 11 & 12 \\
\hline C. tropicalis & 0 & 2 & 2 \\
\hline C. dublinensis & 0 & 8 & 9 \\
\hline $\begin{array}{l}\text { Unidentifiable } \\
\text { spp. }\end{array}$ & 19 & 0 & 0 \\
\hline Total & 40 & 40 & 40 \\
\hline
\end{tabular}

Table 2: Comparing sensitivity and specificity of germ tube test and CHROMagar.

\begin{tabular}{|c|c|c|c|c|}
\hline \multicolumn{3}{|c|}{ Polymerase chain reaction } & \multirow[t]{2}{*}{ Sensitivity } & \multirow[t]{2}{*}{ Specificity } \\
\hline C.albicans & + ve $C$. albicans & - ve $C$. albicans & & \\
\hline GTT positive $=21$ & 17 & 4 & \multirow[t]{2}{*}{$94.4 \%$} & \multirow[t]{2}{*}{$81.8 \%$} \\
\hline GTT negative $=19$ & 1 & 18 & & \\
\hline CHROMagar positive $=19$ & 17 & 2 & \multirow{2}{*}{$94.0 \%$} & \multirow{2}{*}{$81.0 \%$} \\
\hline CHROMagar negative $=21$ & 2 & 19 & & \\
\hline C. dublinensis & +ve C. dublinensis & -ve C. dublinensis & & \\
\hline CHROMagar positive $=9$ & 8 & 1 & \multirow{2}{*}{$88.9 \%$} & \multirow{2}{*}{$96.8 \%$} \\
\hline CHROMagar negative $=31$ & 1 & 30 & & \\
\hline C. glabrata & +ve C. glabrata & -ve C. glabrata & & \\
\hline CHROMagar positive $=12$ & 11 & 1 & \multirow{2}{*}{$91.6 \%$} & \multirow{2}{*}{$96.2 \%$} \\
\hline CHROMagar negative $=28$ & 1 & 27 & & \\
\hline C. tropicalis & +ve C. tropicalis & -ve C. tropicalis & & \\
\hline CHROMagar positive=2 & 2 & 0 & \multirow{2}{*}{$100 \%$} & \multirow{2}{*}{$100 \%$} \\
\hline CHROMagar negative $=38$ & 0 & 38 & & \\
\hline
\end{tabular}

Key: +ve: Positive; -ve: Negative

Out of 9 strains of $C$. dublinensis that were identified by CHROMagar, 8 were re-identified as true positive by PCR. One (1) from the 31 strains that were identified as negative for $C$. dublinensis was re-identified as positive by PCR method. CHROMagar sensitivity and specificity for C. dublinensis were $88.8 \% \%$ and $96.8 \%$ respectively.

Out of 12 strains of $C$. glabrata that were identified by CHROMagar, 11 were re-identified as true positive by PCR. One (1) from the 28 strains that were identified as negative for $C$. glabrata was re-identified as $C$. glabrata by PCR. CHROMagar sensitivity and specificity for C. glabrata were $91.6 \% \%$ and $96.2 \%$ respectively. Two (2) strains of $C$. tropicalis identified by CHROMagar were confirmed by PCR as true positive.

\section{DISCUSSION}

A previous study revealed a high incidence of asymptomatic vulvovaginal candidiasis among pregnant women in Ogbomoso with infection rate of $25 \% .{ }^{19}$ In a study conducted by Merlino et al. all $C$. albicans were reported to be germ tube positive but two $C$. tropicalis gave false positive results. ${ }^{20}$ In this present study, $52.5 \%$ of the Candida spp isolated were identified as C. albicans using GTT, $47 \%$ were identified by CHROMagar, while $42.5 \%$ were identified by PCR as $C$. albicans. Kazemi et al. reported that $65.4 \%$ of C. albicans was detected by germ tube formation, $53 \%$ by Chlamydoconium formation and $62.4 \%$ by molecular studies. ${ }^{21}$

While germ tube test was not able to identify other species of Candida (47.5\%), CHROMagar identified $27.5 \%, 5.0 \%$ and $20 \%$ as C. glabrata, C. tropicalis and C. dubliniensis respectively; PCR was able to identify $30.0 \%$ C. glabrata, $5.0 \%$ C. tropicalis and $22.5 \%$ C. dubliniensis. Although germ tube test is performed quickly, false positive results by $C$. tropicalis and C. dubliniensis generated by the test and the use of 
potentially dangerous sera are the major drawbacks of the test. $^{22}$

The identification of other species of $C$. albican was bettered with the use of CHROMagar and PCR. Mahens et al. used PCR to differentiate $C$. albicans and C. dubliniensis. They concluded that PCR has the potential of detection in low amounts of DNA and helps the rapid diagnosis of pathogenic fungi that is critical in treatment of candidiasis. ${ }^{23}$

The sensitivity and specificity of germ tube test for C. albicans were $94 \%$ and $81 \%$ respectively. Some authors evaluated and reported sensitivity and specificity of germ tube test as $84.6 \%$ and $100 \%$ respectively. ${ }^{24}$ Hoppe et al. estimated both specificity and sensitivity as $98 \% .^{25}$

Of 19 strains of $C$. albicans that were identified by CHROMagar, 17 were confirmed as true positive by PCR while 2 were false positive. The CHROMagar had $89.4 \%$ sensitivity and $90.4 \%$ specificity. In comparison, GTT was better in correctly identifying those strains that were confirmed as C. albicans by PCR (Sensitivity=94\%) while CHROMagar was better in identifying the strains that were not confirmed as $C$. albicans by PCR $($ Specificity $=90.4 \%)$.

In this study, the identification of Candida isolates was performed successfully using germ-tube test, CHROMagar test and PCR. The isolated Candida species were C. albicans, C. tropicalis, C. glabrata and C. dubliniensis. In a comparison among PCR, germ-tube, and CHROMagar test results, all three assays confirmed the presence of $C$. albicans, but germ-tube test did not confirm the identity of 19 other Candida isolates. Therefore, this study shows the best specificity of CHROMagar over the GTT Method, when compared with the PCR Method. The combine use of CHROMagar and PCR has the advantage of efficient detection of various Candida isolates thus; the use of PCR is technically demanding.

\section{CONCLUSIONS}

Even though CHROMagar method had so long been established, however, the use of this method for diagnostic purposes is not common in Nigeria due to the cost implication. Most diagnostic centers in Nigeria report the presence of Candida in a given sample has C. albicans while others will be categorized as Candida spp. We therefore advise that efforts should be intensified to further detect other Candida spp. by using both the CHROMagar and PCR methods in order to improve both diagnostic and treatment outcome of candidiasis among pregnant women. Further studies are however required to appropriately classify the Candida isolates by sequencing the PCR products.

Funding: No funding sources
Conflict of interest: None declared

Ethical approval: The study was approved by the Institutional Ethics Committee

\section{REFERENCES}

1. Eloy O, Marque S, Batterel F, Stephan F, Costa JM, Laserre V, Bretagne S. Uniform distribution of three Candida albicans microsatellite markers in two French ICU populations supports a lack of nosocomial cross-contamination. BMC Infect Dis. 2006;6:162-3.

2. Kamiya A, Tomita Y, Kikuchi A, Knabe T. Epidemiological study of Candida species in cutaneous candidiasis based on PCR using a primer mix specific for the DNA topoisomerase II gene. J Dermatol Sci. 2005;21-8.

3. Anaissie EJ, McGinnis MR, Pfaller MA. Clinical Mycology, Philadelphia: Elsevier Sciences; 2003.

4. Rippon JW. Medical Mycology. The pathogenic fungi \& actinomycetes. Philadelphia:W.B. Saunders Co; 1988.

5. Edmond MB, Wallace SE, Mc Clish DK, Pfaller MA, Jones RN, Wenzel RP. Nosocomial bloodstream infections in United States hospitals: a three-year analysis. Clin Infec Dis. 1999;29(2):23944.

6. Hedayati T, Shafiei G. Candidiasis. eMedicine Specialties. 2010.

7. Das Neves J, Pinto E, Teixeira B, Dias G, Rocha P, Cunha T. Local treatment of vulvovaginal candidosis: general and practical considerations. Drugs. 2008;68(13):1787-802.

8. Eschenbach DA. Chronic vulvovaginal candidiasis. N Engl J Med. 2004;351(9):851-2.

9. Monif GR, Baker DA. Candida albicans. In: Monif GR, Baker DA, editors. Infectious diseases in obstetrics and gynecology. 5th ed. New York, NY: Parthenon Press; 2003.

10. Baron EJ, Cassell GH, Duffy LB, Eschenbach JR, Greenwood SM, Harvey NE. Laboratory diagnosis of female genital tract infections. In: Baron EJ, editor. Cumulative techniques and procedures in clinical microbiology (Cumitech); 1993.

11. Carlson P, Richardson M, Paavonen J. Evaluation of the oricult-N Dipslide for laboratory diagnosis of vaginal candidiasis. J Clin Microbiol. 2000;38(3):1063-5.

12. Guthrie BL, Kiariae JN, Morrison S, John-Stewart GC, Kimuthia J, Whittington WLH, Farquhar C. Sexually transmitted infections among HIV-1discordant couples. PLoS One. 2009;4(12):8276.

13. Ahmad S, Khan Z, Mustafa AS, Khan ZU. Seminested PCR for diagnosis of candidemia: comparison with culture, antigen detection, and biochemical methods for species identification. J Clin Microbiol. 2002;40(7):2483-9.

14. Cheesbrough M. Microbiological test in; District laboratory practice for tropical countries part 2, 
Cambridge Low Price Edition, Cambridge University Press; 2000.

15. Baker F. Handbook of bacteriological techniques. $2^{\text {nd }}$ ed. Butterworth Co. ltd London; 1967.

16. Mohamed SA, Al-Ahmadey ZZ. Biofilm formation and antifungal susceptibility of Candida isolates from various clinical specimens. Brit Micribiol Res J. 2013;3(4):590-601.

17. Metwally L, Fairly DJ, Coyle PV,Hay RJ, Hedderwick S, McCloskey B,O’Neill HJ,Webb $\mathrm{CH}$,Elbaz Wand McMullan R. Improving molecular detection of Candida DNA in whole blood: comparison of seven fungal DNA extraction protocols using real-time PCR. J. Med. Microbiol. 2008;57:296-303.

18. Mousavi SA, Salari S, Rezaie S, Shahabi N, Nejad NS, Hadizadeh S, Kamyabi $\mathrm{H}$, Aghasi $\mathrm{H}$. Identification of Candida species isolated from oral colonization in Iranian HIV-positive patients, by PCR-RFLP method. Jundishapur J Microbiol. 2012;5(1):336-40.

19. Akinbami AN, Babalola GO, Shittu MO, Tijani AM, Adekola SA. Detection and epidemiology of vulvovaginal candidiasis among asymptomatic pregnant women attending a tertiary hospital in Ogbomoso, Nigeria. Intern $\mathrm{J}$ Biomed Res. 2015;6(07):518-23.

20. Merlino J, Tambosis E, Veal D. Chromogenic tube test for presumptive identification or confirmation of isolates as Candida albicans. J Clin Microbiol. 1998;36(4):1157-9.

21. Kazemi A, Falahati M, Hajipoor A, Jafari A, Asgharzadeh M. Comparison of phenotypic tests and PCR to detect Candida albicans from vaginal specimens. Jundishapur J Microbiol. 2013;6(2):122-6.

22. Yucesoy M, Esen N, Yulug N. Use of chromogenic tube and methyl blue-sabouraud agar for the identification of Candida albicans strains. Kobe J Med Sci. 2001;47(4):161-7.

23. Mahens B, Stehr F, Schafer W, Neuber K. Comparison of standard phenotypic assays with a PCR method to discriminate Candida albicans and C. dubliniensis. Mycoses. 2005;48(1):55-61.

24. Ainscough S, Kibbler CC. An evaluation of the costeffectiveness of using CHROM agar for yeast identification in a routine microbiology laboratory. $\mathrm{J}$ Med Microbiol. 1998;47(7):623-8.

25. Hoppe JE, Frey P. Evaluation of six commercial tests and the germ-tube test for presumptive identification of Candida albicans. Eur J Clin Microbiol Infect Dis. 1999;18(3):188-91.

Cite this article as: Nurat AA, Ola BG, Olushola SM, Mikhail TA, Ayodeji AS. Molecular and phenotypic identification of Candida isolates from pregnant women in Ogbomoso, Southwestern Nigeria. Int J Reprod Contracept Obstet Gynecol 2016;5:317-22. 